\title{
Daya dukung iklim organisasi sekolah terhadap motivasi guru
}

\section{(The carrying capacity of school organizational climate towards teacher motivation)}

\author{
Febia Putri Kurniawati', Uep Tatang Sontani ${ }^{2^{*}}$ \\ 1,2 Program Studi Pendidikan Manajemen Perkantoran \\ Fakultas Pendidikan Ekonomi dan Bisnis, Universitas Pendidikan Indonesia, \\ Jl. Dr. Setiabudhi, No. 229 Bandung, Jawa Barat Indonesia \\ Email: ueptatangsontani@upi.edu
}

\begin{abstract}
ABSTRAK
Bertitik tolak dari kondisi empirik bahwa kadar motivasi yang ada dan dialami oleh setiap individu anggota organisasi tidaklah bersifat stagnan, melainkan bersifat fluktuatif, dalam artian terkadang berada pada posisi kuat atau sebaliknya berada pada posisi lemah, hal tersebut sangat bergantung kepada kuat lemahnya factor stimulus yang diterima sumber daya manusia. Yang menjadi persoalan adalah manakala motivasi itu berada pada posisi lemah. Keadaan demikian akan berdampak tidak baik bagi kehidupan organisasi di masa-masa mendatang. Dalam konteks organisasi sekolah, iklim merupakan bagian dari unsur stimulus eksternal motivasi sumber daya manusia, siapapun termasuk di dalamnya adalah para pendidik. Mengingat bahwa iklim organisasi sekolah memberikan berpengaruh terhadap motivasi guru dalam bekerja, maka dapat dinyatakan bahwa iklim organisasi sekolah memiliki daya dukung yang nyata terhadap motivasi guru meskipun dalam kasus penelitian yang dilakukan dukungannya kecil.
\end{abstract}

Kata Kunci: Iklim Organisasi Sekolah; Motivasi Guru

\begin{abstract}
Base on empirical condition that motivation capacity is not stagnant but fluctuative for every body as member of organization, in meaning sometime strong position or opposite is weak, that are depend on strong or weakness the stimulus factor received by human resousrces. That will to be problem when the motivation being weak position. Thus will effect bad for organization life in future. In the school organization context, the climate is element part of external motivation of human resources any body include the teacher.Rembering that school organization climateis is given effect to the teacher motivation in work, so we can state that school organization climate have empirical support to the teachers motivation in spite of research case have done that the support is litle bite.
\end{abstract}

Keyword : Organization Climate; Teacher Motivation

Received: Februari 2019, Revision: Mei 2019, Published: Juli 2019

*Corresponding author

Copyright @ 2019, EISSN 2656- 4734 


\section{PENDAHULUAN}

Permasalahan motivasi merupakan isu yang senantiasa aktual dan menarik, tampil mengemuka di bicarakan khalayak ramai termasuk para akademisi di perguruan tinggi. Motivasi sebagai konsep psikologis yang bersifat dinamis, prinsip-prinsipnya berlaku universal dalam tataran aplikasi secara empiric pada kehidupan masyarakat baik secara individu atau bagian dari anggota organisasi. Kedinamisan motivasi sebagai konsep psikologis tidak lepas dari adanya perubahan pola kehidupan masyarakat akibat terjadinya perkembangan ilmu pengetahuan dan teknologi (IPTEK) yang sangat pesat, dan globalisasi yang melanda dunia sebagai suatu keniscayaan yang tidak dapat dihindari manusia. Langsung maupun tidak langsung hal itu telah menimbulkan permasalahan di dalam kehidupan masyarakat itu sendiri, termasuk dalam hal ini kehidupan pada organisasi sekolah.

Permasalahan yang dihadapi organisasi sekolah sesungguhnya sangat banyak, salah satunya adalah tentang motivasi guru yang belum optimal dalam melaksanakan tugas-tugasnya terutama dalam tugas pembelajaran. Fenomena yang terdeteksi antara lain bahwa guru yang seharusnya memberikan keteladanan dalam disiplin terhadap waktu untuk melaksanakan tugas, namun faktanya tidak sedikit dari mereka yang justru sering hadir ke kelas tidak tepat waktu alias kesiangan, Hal lainnya adalah kurangnya dukungan kepala sekolah terhadap para guru dalam melaksanakan pekerjaannya.

Kondisi demikian tentunya tidak baik di biarkan terus berlanjut karena dampak yang akan terjadi adalah semakin buruknya kehidupan organisasi di masa-masa mendatang, dan bukan hal mustahil jika pada akhirnya akan berdampak pula terhadap kualitas output atau para lulusan sekolahnya menjadi rendah. Kualitas lulusan yang rendah berdampak pada daya saingnya yang lemah, sehingga tersingkir dari arena persaingan kerja yang semakin hari semakin sengit.

Sehubungan dengan hal tersebut kiranya perlu dicari solusi dengan menggali secara komprehensif faktor - faktor penyebab belum optimalnya motivasi guru tersebut. Dari penelusuran yang di lakukan terhadap beberapa sekolah khususnya 2 Sekolah Menengah kejuruan (SMK) di daerah Kota Bandung, ternyata faktor iklim organisasi sekolah di duga kuat sebagai penyebab munculnya permasalahan motivasi guru tersebut, Atas dasar hal tersebut permasalahan yang akan dipecahkan melalui penelitian mikro ini adalah bermaksud menjawab pertanyaan tentang bagaimana sesungguhnya daya dukung iklim organisasi sekolah terhadap motivasi para pendidik.

\section{TINJAUAN PUSTAKA \\ Iklim Organisasi Sekolah \\ Definisi Iklim Organisasi Sekolah}

Konsep iklim organisasi (organizational climate) pertama kalinya diperkenalkan oleh Kurt Lewin pada tahun 1930-an, dengan memakai sebutan iklim psikologi (psychologi climate), selanjutnya iklim organisasi digunakan oleh R. Tagiuri dan G. Litwin, sebagaimana dikutip oleh Wirawan (2007, hlm. 10) yang menyatakan bahwa "iklim organisasi merupakan kualitas lingkungan internal yang secara relatif terus berlangsung dialami oleh anggota organisasi, mempengaruhi perilaku setiap anggotanya". 
Menurut Elviera Sari dalam Jurnal Ilmu Administrasi dan Organisasi (2009, hlm. 20) Iklim (climate) selalu dilihat sebagai descriptive concept yang tertuju pada fakta tentang lingkungan. Iklim organisasi dipandang pula sebagai suatu sistem sosial yang selalu dipengaruhi oleh lingkungan baik internal maupun eksternal. Iklim organisasi yang baik penting untuk diciptakan karena merupakan persepsi seorang karyawan tentang apa yang diberikan oleh organisasi dan dijadikan dasar bagi penentuan tingkah laku karyawan selanjutnya. Oleh karena itu iklim organisasi merupakan hal yang krusial dan berdampak pada motivasi individu dalam pencapaian suatu hasil.

Bertolak dari batasan-batasan di atas dapat disimpulkan bahwa iklim organisasi sekolah merupakan suasana atau keadaan yang terjadi di lingkungan sekolah. Iklim organisasi sekolah bisa dipandang dari tiga sisi, yaitu lingkungan fisik sebagai lingkungan yang berkaitan dengan kondisi fisik sekolah dari segi bentuknya hal tersebut terkait dengan bagaimana fisik bangunannya ruangannya, dan juga halamannya. Lingkungan sosial berkaitan dengan hal tentang bagaimana relasi yang terjadi diantara semua orang sebagai warga dari sekolah. Lingkungan organisasional dimaksudkan sebagai perangkat organisasi berkaitan dengan posisi maupun susunan organisasi secara struktural dari organisasi sekolah.

\section{Indikator Iklim Organisasi Sekolah}

Yang dimaksud dengan Indikator dalam hal ini adalah hal-hal yang bisa memberikan penjelasan atau petunjuk terhadap sesuatu atau memberikan ciri-ciri tertentu terhadap sesuatu.

Iklim organisasi sekolah merupakan konsep yang bersifat abstrak, bagaimana cara mengukur iklim oganisasi tersebut, maka konsep tersebut perlu dijabarkan ke dalam konsep yang bersifat operasional. Terkait dengan hal tersebut Likert telah mengembangkan instrumen pengukur iklim organisasi yang mencakup unsur-unsur sebagai berikut : 1) Kualitas kepemimpinan, 2) kadar kepercayaan, 3) komunikasi ke atas dan ke bawah, 4) perasaan melakukan pekerjaan yang bermanfaat, 5) tanggung jawab, 6) imbalan yang adil, 7) tekananan pekerjaan yang nalar, 8) pengendalian struktur dan birokrasi yang nalar, 9) keterelibatan pegawai, dan 10) keikutsertaan."

Sementara menurut Robert Stringer yang di kutip oleh Warawan (2007, hl, 131133) mengemukakan bahwa dalam mengukur iklim organisasi ada lima hal yang bisa dijadikan acuan yaitu sebagai berikut :

1. Structure

2. Standards

3. Recognition

4. Support

5. Commitment

\section{Motivasi Guru \\ Definisi Motivasi Guru}

Motivasi (motivation) sering diartikan sebagai suatu dorongan yang menjadikan sesorang melakukan suatu tindakan atau perbuatan tertentu. Berkaitan dengan konsep motivasi Malayu P Hasibuan (2008, hlm. 95) berpendapat bahwa "Motivasi pada dasarnya pemberian daya penggerak yang menciptakan kegairahan kerja seseorang, agar mereka mau bekerja sama, bekerja efektif dan terintegrasi dengan segala daya upayanya menciptakan kepuasan dan tujuan." Sementara M. Dalyono 
(2005, hlm 55) mengemukakan bahwa "motivasi adalah daya penggerak/pendorong untuk melakukan sesuatu pekerjaan, yang bisa berasal dari dalam diri dan juga dari luar."

Dari batasan-batasan di atas dapat dirangkum bahwa motivasi berasal dari dua sumber yakni sumber internal dan sumber eksternal. Dalam konteks organisasi, motivasi eksternal merupakan tindakan yang dilakukan oleh pemimpin terhadap bawahannya. Hal tersebut merupakan relasisasi dari fungsi penggerakan dalam manajemen berkaitan dengan tugas pemotivasian dan komunikasi serta mempengaruhi bawahan agar bersedia bekerja guna tercapainya tujuan organisasi.

Terdapat kurang lebih tiga model atau pendekatan motivasi yaitu model tradisional, model hubungan antar mausia, dan model sumber daya manusia. Model tradisional menekankan bahwa para pekerja melakukan tugasnya yang menjenuhkan dan berulang-ulang dengan cara yang efisien. Asumsi model ini adalah bahwa pekerja pada dasarnya pemalas sementara para manajer memahami pekerjaan karyawan lebih baik daripada karyawan itu sendiri. Model hubungan antar manusia menekankan bahwa manajer bias memotivasi para bawahannya dengan cara mengakui kebutuhan sosialnya, menjadikan mereka merasa penting dan bermanfaat. Model sumber daya manusia menekankan bahwa para pekerja sebenarnya telah di motivasi guna melakukan pekerjaan yang baik dan mereka tidak dengan sendirinya memandang pekerjaan sebagai sesuatu yang tidak diharapkan. Para pekerja ada kemungkinan mendapatkan kepuasan dari prestasi kerjanya. Penghargaan terhadap sisi kemanusiaan dapat diberi tanggung jawab yang besar guna mengambil putusan dan melakukan pekerjaannya.

\section{Indikator Motivasi Guru}

Motivasi guru dapat diukur dari beberapa unsur antara lain sebagai berikut : disiplin, semangat kerja, ambisi, kompetensi dan kerja keras (Hasibuan, 2007, hlm. 183).

Menurut Herzberg (dalam Ivancevich, dkk, 2006, hlm. 123) terdapat serangkaian kondisi intrinsik yang dapat membentuk motivasi yang kuat sehingga dapat menghasilkan kinerja yang baik.

Indikator motivasi sebagai berikut :

1. Prestasi

Aspek ini berhubungan dengan usaha yang dilakukan seseorang untuk mencapai prestasi kerja yang optimal.

2. Tanggung jawab

Aspek ini meliputi hal-hal yang berhubungan dengan tanggung jawab dan otoritas pada karyawan.

3. Kemajuan

Aspek ini berhubungan dengan kesempatan karyawan untuk dapat maju dalam pekerjaannya.

4. Pekerjaan itu sendiri

Aspek ini berhubungan dengan tantangan yang dirasakan karyawan dari pekerjaannya. 


\section{PENGARUH IKLIM ORGANISASI SEKOLAH TERHADAP MOTIVASI GURU}

Tidak sedikit unsur yang berhubungan dengan motivasi guru dalam bekerja, salah satunya adalah unsur eksternal sumber daya manusia berupa iklim organisasi sekolah. Disadari atau tidak disadari bahwa iklim organisasi sekolah tersebut memiliki peranan penting yang tidak bisa diabaikan begitu saja oleh karena iklim organisasi sekolah mendorong guru untuk giat dalam bekerja lebih baik.

Sagala (2009, hlm. 130) menjelaskan bahwa " iklim organisasi meliputi dimensi adanya rasa tanggung jawab, standar atau harapan tentang kualitas pekerjaan, reward yang diperoleh sebagai pengakuan terhadap prestasi, saling mendukung dalam melaksanakan pekerjaan, dan semangat yang kuat dalam tim kerja". Dimensi-dimensi tersebut pada gilirannya nanti akan mempengaruhi motivasi para guru di sekolah dan berdampak pada kinerjanya.

Robert Stringer (2000) dalam Wirawan (2007, hlm. 131) mengemukakan bahwa "karakteristik atau dimensi iklim organisasi mempengaruhi motivasi anggota organisasi untuk berperilaku tertentu". Pernyataan tersebut didukung oleh pendapat Davis (1996: 23) yang menyebutkan bahwa iklim dapat mempengaruhi motivasi, prestai dan kepuasan kerja.

Berdasarkan paparan tinjauan teori di atas dapatlah disimpulkan bahwa iklim organisasi sekolah berpengaruh langsung terhadap motivasi guru. proposisi tersebut dapat disederhankan dalam model hubungan berikut:

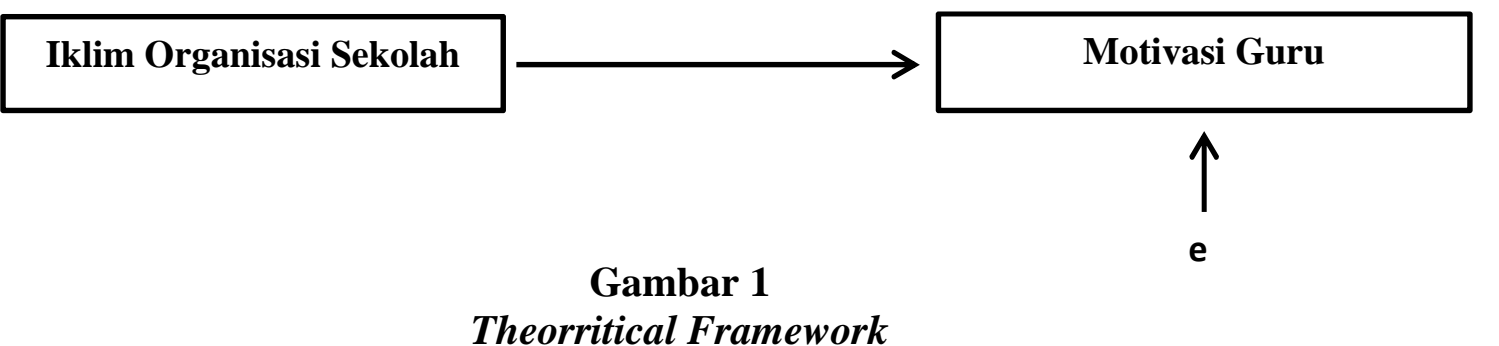

Berdasarkan bagan model di atas dapat d rumusan hipotesis penelitian berikut:

"Adanya daya dukung iklim organisasi sekolah terhadap motivasi guru"

\section{METODE PENELITIAN}

Metode yang di gunakan dalam penelitian ini adalah survey eksplanatory sementara teknik pengumpulan datanya memakai instrumen kuesioner berskala lima. Model Liker tang di modifikasi. Terdapat dua bagian kuesioner yang disampaikan kepada responden. Bagian kesatu kuesioner untuk mengungkap data iklim organisasi sekolah yang memuat 5 unsur, yaitu Struktur (Structure), Standar-standar (Standards), Penghargaan (Recognition), Dukungan (Support), dan Komitmen (Commitment) Ke lima unsur tersebut di jabarkan ke dalam 16 bulir kuesioner. Bagian berikut adalah kuesioner untuk menggali data motivasi guru yang mencakup 4 unsur yaitu Prestasi, Tanggung jawab, Kemajuan, dan Pekerjaan itu sendiri. Keempat unsur tersebut di jabarkan ke dalam pernyataan kuesioner sebanyak 13 item.

Responden penelitian ini adalah guru-guru di dua SMK swasta yang ada di Kota Bandung berjumlah 70 orang. Teknik pengolahan data yang dipakai adalah regresi 
linier sederhana.Secara teknis pengolahan data peneltian ini memakai bantuan Software SPSS (Statistic Product and Service Solutions) version 22.0.

\section{HASIL PENELITIAN}

\section{Iklim Organisasi Sekolah Sebagai Determinasi Motivasi Guru}

Untuk melihat dampak variabel iklim organisasi sekolah terhadap motivasi guru maka dianalisis dengan statistik inferensial menggunakan perhitungan analisis regresi sederhana. Diperoleh persamaan regresi: $\widehat{Y}=18,078+0,489 \mathrm{X}$. Tanda positif (+) menunjukkan hubungan antara variabel bebas dengan variabel terikat berjalan dengan satu arah. Artinya, setiap peningkatan atau penurunan di satu variabel akan diikuti oleh peningkatan atau penurunan di satu variabel lainnya. Sehingga apabila semakin kondusif iklim organisasi sekolah, maka semakin tinggi pula motivasi guru, begitu pula sebaliknya.

Berdasarkan hasil perhitungan dalam pengujian hipotesis diperoleh nilai kritis pada $\mathrm{db}=\mathrm{n}-2$ dan $\alpha=0.05$, yaitu $\mathrm{t}(0.05,70)=1.996$. Berdasarkan nilai t hitung diketahui nilai t hitung lebih besar dari t tabel 6,619>1,996, sehingga pernyataan "Daya Dukung Iklim Organisasi Sekolah terhadap Motivasi Guru" diterima.

Koefisien korelasi antar variabel iklim organisasi sekolah dengan motivasi guru, yakni sebesar 0.626. Artinya, hubungan antar variabel iklim organisasi sekolah dengan motivasi guru berada pada kadar hubungan yang kuat/tinggi. Besaran koefisien daya dukung iklim organisasi sekolah terhadap motivasi guru, sebagaimana ditunjukkan pada perhitungan koefisien determinsi adalah sebesar 39,2\%, Besaran koefisien tersebut sesunguhnya kecil, namun demikian daya dukung yang terjadi adalah nyata atau signifikan.

\section{KESIMPULAN}

Iklim organisasi adalah suatu unsur eksternal yang berpengaruh terhadap motivasi sumber daya manusia. Dengan kata lain iklim Organisasi sekolah memiliki daya dukung yang kuat dan nyata terhadap motivasi guru. Semakin kondusif iklim organisasi sekolah, maka semakin meningkat kadar motivasi guru dalam bekerja.

\section{DAFTAR PUSTAKA}

Dalyono, D. M. (2005). Motivasi Kepemimpinan dan Efektivitas Kelompok. Jakarta: PT. Rineka Cipta Utama.

Davis Keith \& John W Newstrom (1996 ) Perilaku Dalam Organisasi, edisi ketujuh Erlangga Jakarta

Hasibuan, M. P. (2007). Manajemen Sumber Daya Manusia. Jakarta: Bumi Aksara.

Hasibuan, M. P. (2008). Manajemen Sumber Daya Manusia Edisi Revisi PT. Bumi Aksara. Jakarta: PT. Bumi Aksara.

Ivancevich, D. G. (2006). Organisasi, Perilaku, Struktur, Proses. Jakarta: Bina Rupa Angkasa.

Sagala, S. (2009). Konsep Dasar Makana Pembelajaran. Bandung: Alfabeta. 
Sari, E. ((Jan-Apr 2009)). Pengaruh Kompensasi dan Iklim Organisasi terhadap Kepuasan Kerja. Jurnal Ilmu Administrasi dan Organisasi, 20.

Toulson, P. d. (1994). The Relationship Between Organizational Climate and Employee Perceptions of Personal Management Practice. Journal Public Relations Management.

UU RI Nomor 20 tentang Sistem Pendidikan Nasional Tahun 2003

Peraturan Pemerintah Nomor 16 Tahun 2007

Wirawan. (2007). Motivasi dan Pemotivasi dalam Manajemen. Jakarta: PT. Raja Grafindo. 